Article

\title{
Studies on the Oxidation Behavior of a Designed Nanocrystalline Coating on K38 Alloy at $1050{ }^{\circ} \mathrm{C}$
}

\author{
Jinlong Wang ${ }^{1} \oplus$, Bo Meng ${ }^{1}$, Wenyao Sun ${ }^{1}$, Lanlan Yang ${ }^{2, *}$, Minghui Chen ${ }^{1} \mathbb{C}$ and Fuhui Wang ${ }^{1}$ \\ 1 Shenyang National Laboratory for Materials Science, Northeastern University, Shenyang 110819, China; \\ wangjinlong@mail.neu.edu.cn (J.W.); 1910132@stu.neu.edu.cn (B.M.); wysun15s@imr.ac.cn (W.S.); \\ mhchen@mail.neu.edu.cn (M.C.); fhwang@mail.neu.edu.cn (F.W.) \\ 2 School of Materials Science and Engineering, Jiangsu University of Science and Technology, \\ Zhenjiang 212003, China \\ * Correspondence: lanlanyang@just.edu.cn; Tel.: +86-24-23904856; Fax: +86-24-23893624
}

Received: 14 November 2020; Accepted: 1 December 2020; Published: 4 December 2020

\begin{abstract}
A new framework for a nanocrystalline coating system is established and prepared to study the oxidation behavior with a significant difference in elemental composition. K38 superalloy is selected as a substrate alloy and the composition of the 2nd-generation single-crystal superalloy Rene N5 is used as the sputtered nanocrystalline coating. The oxidation behavior of the newly designed nanocrystalline coating is comparatively studied with the original K38 coating and its substrate alloy at $1050{ }^{\circ} \mathrm{C}$ for $500 \mathrm{~h}$. Moreover, microstructure evolution on the interface is used for studying the influence of element interdiffusion behavior on the substrate alloy. Results show that the nanocrystalline coatings increase the oxidation performance of alloys at $1050{ }^{\circ} \mathrm{C}$ for $100 \mathrm{~h}$. The sputtered SN-N5 nanocrystalline coating exhibits the best oxidation resistance among the three groups of specimens for $500 \mathrm{~h}$. Interdiffusion occurred and is observed on the SN-N5 coating after long-term oxidation. However, no topologically close-packed phases participated in the substrate alloy.
\end{abstract}

Keywords: superalloy; nanocrystalline coating; high temperature oxidation; interdiffusion; oxidation behavior

\section{Introduction}

Nickel-based superalloys have been developed specifically for high-temperature applications for use in industrial gas turbines, aircraft and jet engines [1,2]. As the inlet temperature continuous to rise, improve the organization structure and element component content of superalloy has attracted increasing attention due to its influence on the performance by solution strengthen, coherence strengthening with $\gamma / \gamma^{\prime}$ and forging process upgrading [3-6]. However, the requirement for improving the mechanical properties leads to a trend of higher refractory elements addition, such as Mo, W, Re and Ta, which results in a decreasing in the oxidation resistance $[7,8]$. Thus, the degradation of composition and structure directly affects the service life of the superalloy under high temperature. Research on how to improve the oxidation resistance has been widely undertaken in recent years [9-13]. Most of all, developing a high-temperature protective coating is the most convenience method on improving the oxidation resistance against the high-temperature environment.

The application of the traditional $\beta 2$ or MCrAlY coating can improve the oxidation resistance of the substrate alloy under a high-temperature environment by the Physical Vapor Deposition (PVD) or Chemical Vapor Deposition (CVD) methods [14-16]. It is well established that the oxidation resistance of the coatings is largely dictated by the ability to preferentially from an adherent $\mathrm{Al}_{2} \mathrm{O}_{3}$ or $\mathrm{Cr}_{2} \mathrm{O}_{3}$ scale on their surfaces. However, due to the traditional structure and composition design characteristics of $\beta 2$ coatings, the problems of oxide scale, such as it easily peeling off $[17,18]$, obvious 
surface rumpling $[19,20]$ and serious interdiffusion $[21,22]$ are often met. The application of coatings often faces limitations at higher temperature. As a new type of high-temperature protective coating, the nanocrystalline coating has unique design in composition and structure, and exhibits excellent high oxidation resistance [23-27]. That is, the nanoscale columnar grains provide numerous diffusion paths of $\mathrm{Al}$, which rapidly forms a compact aluminide layer at high temperature [23,24]. In addition, the coating and its scale exhibit good plastic performance and, thus, increase the adhesion property of the oxide layer $[25,26]$. It is noteworthy that the balanced element characteristic in a nanocrystalline coating cannot form brittle TCP (topologically close-packed) phases that those traditional coatings form, which affects the high-temperature mechanical properties of the alloy little [27-29].

In our previous study, the application of a nanocrystalline coating generally increases the serving temperature of substrate alloy about $50 \sim 150{ }^{\circ} \mathrm{C}$, in other words, it can endow the ability to enhance the oxidation resistance of the alloy at a higher temperature [27-30]. Although it does not face the serious problems that traditional coatings perform, there exist a few defects which make the oxidation performance imperfect. If, for instance, substantial quantity of refractory elements in the coating always had comparable activities to $\mathrm{Al}$ when serving higher at its activation temperature, then severe elements (Ta, Ti) segregation at scale would cause a negative effect on oxidation resistance [31,32]. Furthermore, the design of low $\mathrm{Al}$ and $\mathrm{Cr}$ contents in the coating cannot complete sustaining protection due to the limitation of elements of the depleted area after long-term oxidation [33,34]. Recently, we improved the properties of nanocrystalline coatings by regulating the content of $\mathrm{Al}$ elements or applying the modification of adding reactive elements to resolve these issues [27]. Adding a moderate content of $\mathrm{Al}$ or reactive elements can significantly improve the ability to form $\mathrm{Al}_{2} \mathrm{O}_{3}$, enhancing the purity and the adhesion properties of the oxide scale significantly. Although there are no TCP phases observed at the coating/substrate interface after oxidation, whether the change of composition in the coating will affect the mechanical properties of the alloy remains to be studied.

To study the oxidation and interdiffusion behaviors with a great difference in elemental composition between the nano-structure coating and alloy, in this study, K38 superalloy is selected as substrate, which is a chromia-forming group and the optimal temperature for its use is $900-1000{ }^{\circ} \mathrm{C}$ [35]. A comparative study is designed and investigated between the ordinary sputtered nanocrystalline coating that Lou designed in 1992 [36] and a new framework of nanocrystalline coating. The composition of the 2nd-generation single-crystal superalloy Rene N5 is using as the sputter target for new design nanocrystalline coating [37]. More refractory components are added to the composition design characteristics compared with the $\mathrm{K} 38$, and the content of the $\mathrm{Cr}$ elements is substantially reduced. This work constitutes in fact a continuation of our study concerning the understanding of the elements contents effects on interdiffusion and the oxidation protective mechanism. After the oxidation test, the effects of on the service properties, diffusion distribution of elements and microstructure evolution of the alloy are discussed in detail.

\section{Materials and Methods}

The cast K38 superalloy was chosen as the substrate for the coating deposition. The superalloy was designed and produced in the IMR (Institute of Metal Research, Chinese Academy of Sciences, Shenyang, China), and its nominal composition was shown in Table 1 . The superalloy was melted in a vacuum induction furnace and cast into a plate $2 \mathrm{~mm}$ thick. Specimens of $15 \times 10 \times 2 \mathrm{~mm}^{3}$ were machined from the K38 plate. They were ground down to 400 grit using $\mathrm{SiC}$ papers and sand-blasted with $\mathrm{SiO}_{2}$ under a pressure of $0.4 \mathrm{MPa}$. Then they were degreased by an ultrasonic cleaner in acetone and ethanol. After finishing the surface treatment, the specimens were divided into three groups: (1) one group was directly thrown into muffle furnace for oxidation and denoted the K38 substrate; the other two groups of specimens were prepared for sputtering nanocrystalline coatings. (2) One target used for sputtering the nanocrystalline coating was a $382 \times 128 \mathrm{~mm}^{2}$ sheet with the same composition of K38 superalloy and denoted as SN-K38. (3) The other target was chosen as the composition of the 2nd-generation single-crystal superalloy N5. The nominal composition of the N5 target was shown in 
Table 2. The group of the sputtered coating with the coating composition of N5 was denoted as SN-N5. The coatings were prepared by magnetron sputtering deposition. The base pressure of the vacuum chamber before sputtering the coating is approximately $6 \times 10^{-3} \mathrm{~Pa}$. Sputtering parameters were as follows: argon pressure was $0.24 \mathrm{~Pa}$; sputtering current: $3.5 \mathrm{~A}$; substrate temperature: $200{ }^{\circ} \mathrm{C}$. During the sputtering process, the samples were rotated in front of the target to ensure better uniformity. After the coating deposited for $11 \mathrm{~h}$, the coating thickness was approximately $30 \mu \mathrm{m}$.

Table 1. Nominal composition of the superalloy K38 (wt.\%).

\begin{tabular}{cccccccccccc}
\hline $\mathbf{N i}$ & $\mathbf{C}$ & $\mathbf{C r}$ & $\mathbf{C o}$ & $\mathbf{W}$ & $\mathbf{M o}$ & $\mathbf{A l}$ & $\mathrm{Ti}$ & $\mathbf{F e}$ & $\mathbf{N b}$ & $\mathrm{Ta}$ & $\mathrm{Zr}$ \\
\hline Bal & $0.1-0.2$ & $15.7-16.3$ & $8-9$ & $2.4-2.8$ & $1.5-2$ & $3.2-3.7$ & $3.0-3.5$ & $\leq 0.5$ & $0.6-1.1$ & $1.5-2.0$ & $0.05-0.15$ \\
\hline
\end{tabular}

Table 2. Nominal composition of the N5 nanocrystalline coating (wt.\%).

\begin{tabular}{cccccccc}
\hline Ni & Co & Cr & Mo & W & Ta & Al & Re \\
\hline Bal & 7.5 & 7.0 & 1.5 & 5.0 & 6.5 & 6.2 & 3.0 \\
\hline
\end{tabular}

Each group specimen with four parallel specimens were placed in alumina crucibles for isothermal oxidation test. During the oxidation test, the alumina crucibles should keep constant in weight. Thus, they were all heat-treated in a furnace at $1200{ }^{\circ} \mathrm{C}$ until the weight remain the same. All the specimens were kept at $1050^{\circ} \mathrm{C}$ for different times with wight measurement performed at appointed intervals. The weight of the specimens together with the constant weight alumina crucible was recorded using an electronic balance ( $0.01 \mathrm{mg}$ precision, Sartorius BP211D, Göttingen, Germany). Young's modulus and hardness of substrate alloy and as-deposited coated specimens were measured by a nano-indenter (TI 950 Tribo-Indenter, Hysitron, Minneapolis, MN, USA). The phase constituent was characterized by using X-ray diffraction (XRD, X' Pert PRO, PANalytical Co., Almelo, Holland, $\mathrm{Cu}$ K $\alpha$ radiation at 40 kV). Morphologies and microstructures were examined by scanning electron microscopy (SEM, Inspect F 50, FEI Co., Hillsboro, OR, USA) coupled with an energy-dispersive spectrometer (EDS, X-Max, Oxford instruments Co., Oxford, UK), and by transmission electron microscopy (TEM, JEM-2100F, JEOL, Tokyo, Japan) in conjunction with energy-dispersive X-ray spectroscopy.

\section{Results}

\subsection{Morphologies and Compositions of Coatings before Oxidation}

The fractured and cross-sectional microstructure morphologies and the measured compositions of the as-sputtered nanocrystalline coatings before oxidation are shown in Figure 1. In Figure 1A, the sputtered SN-K38 nanocrystalline coating displayed a columnar structure with an average thickness of about $30 \mu \mathrm{m}$, which presents similar results as references [30,31]. In addition, the TEM bright field cross-sectional results also represented the grain size of the nanocrystalline coating was less than $100 \mathrm{~nm}$, as shown in Figure 1A. The properties of hardness and elastic modulus of alloys and coatings were tested and listed in Table 3. Figure 1B,C presented the cross-sectional structure of the SN-K38 and SN-N5 nanocrystalline coating, respectively. Interfaces of coating/superalloy were well bonded with an obvious banding-like shape. This was due to an initial sand-blasting process aiming at increasing the adhesion strength between substrate and coating [19]. The differences of compositions between the K38 substrate, SN-K38 and SN-N5 coatings were statistics in the form of charts by EDS analysis, as shown in Figure 1D. The results exhibited that there was little difference of elemental composition between the SN-K38 coating and K38 alloy. However, the SN-N5 coating exhibited a substantial difference with the K38 substrate in terms of the oxidation's beneficial contents, where the content of $\mathrm{Cr}$ reached $8.9 \mathrm{wt} . \%$ higher than that contained in N5. Moreover, the total refractory elemental contents in SN-N5 coating reached $6.0 \mathrm{wt} . \%$ higher than the substrate. Notably, the element of titanium and rhenium was not present in the SN-N5 coating and substrate alloy, respectively. 


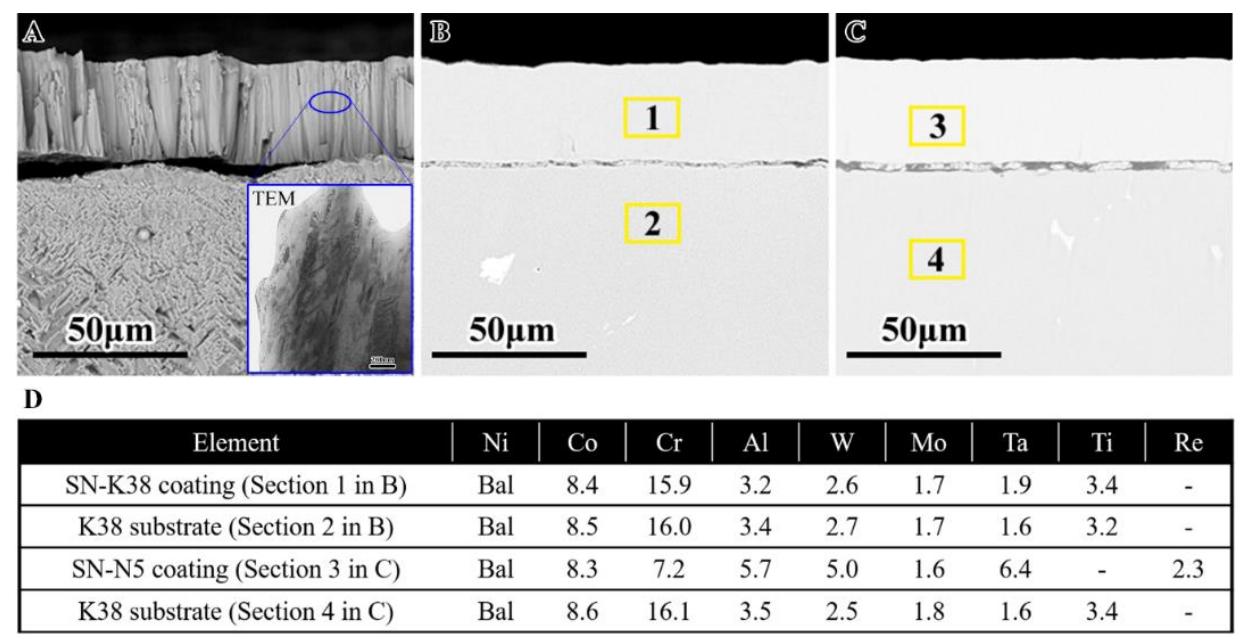

Figure 1. Fractured and transmission electron microscopy (TEM) bright field microstructure (A) and cross-sectional (B) morphologies of the as-sputtered SN-K38 coating, cross-sectional (C) morphology of the as-sputtered SN-N5 coating, (D) chemical composition (wt.\%) measured by energy-dispersive spectrometry (EDS) analysis at the sectional area denoted in $(\mathbf{B}, \mathbf{C})$.

Table 3. Nominal composition of the superalloy K38 (wt.\%).

\begin{tabular}{cccc}
\hline Sample & K38 & SN-K38 & SN-N5 \\
\hline Hardness (GPa) & 9.896 & 10.195 & 9.985 \\
Modulus (GPa) & 242.215 & 255.435 & 256.602 \\
\hline
\end{tabular}

\subsection{Oxidation Kinetics}

Figure 2 shows the oxidation kinetics at $1050{ }^{\circ} \mathrm{C}$ of the superalloy substrate $\mathrm{K} 38$ in comparison with its nanocrystalline coatings. The apparent spallation of oxides would affect the value of weight gain. Thus, isothermal oxidation of the bare alloys and the SN-K38 coating ceased after $100 \mathrm{~h}$ and $200 \mathrm{~h}$ exposure, respectively. As shown in Figure 2A, the substrate alloys exhibited the fastest and highest oxidation rate during the $100 \mathrm{~h}$ oxidation test. After $5 \mathrm{~h}$ of initial oxidation, the mass gains of SN-K38 and SN-N5 coating were comparable. However, both were much lower than the mass gain of K38 substrate. The SN-N5 exhibited the lowest mass gain, where its mass gain was less than two fifths of the SN-K38 coating and only one sixth of the K38 aloy after oxidation for $100 \mathrm{~h}$. Figure 2A shows a function relationship between $\log (y)$ and $\log (t)$, where $y$ denote weight gain and $t$ was oxidation time, which helped to speculate the oxidation regulation of the nanocrystalline coatings. Just as shown in the graph, the slopes of the three curves, $\log (y)$ vs. $\log (t)$, were of almost the same value. When fitting these curves, in order to avoid the influence of initial oxidation, the first point corresponding to $5 \mathrm{~h}$ oxidation was discarded. However, the oxidation did not obey the parabolic law because that the slope was not equal to 0.5 . Indeed, the value of the slope closely to 0.333 , i.e., the oxidation followed the empirical law:

$$
y^{n}=k_{p} t
$$

where $k_{p}$ was rate constant, $\mathrm{n}$ was an empirical exponent $=3$. It has been reported that the empirical exponent of nanocrystalline alloys or coatings larger than two due to their nano-microstructures [32]. As the oxidation time extended to $200 \mathrm{~h}$, the oxidation rate of the SN-K38 coating gradually increased as the alloy was in the last stage, while the growth rate of mass gain closely altered to a straight form. Those might infer that an undesirable unstable oxidation process had taken placed. The mass gain of SN-N5 coating was as well the lowest one as the case during the whole $500 \mathrm{~h}$ test, while no unstable oxidation had occurred for the SN-N5 coating from the view of its oxidation kinetic. As shown in Figure $2 \mathrm{~B}$, its $k_{p}$ value was 10 times lower than that of SN-K38 coating for $100 \mathrm{~h}$ and one third lower during 200-500 h. 
A

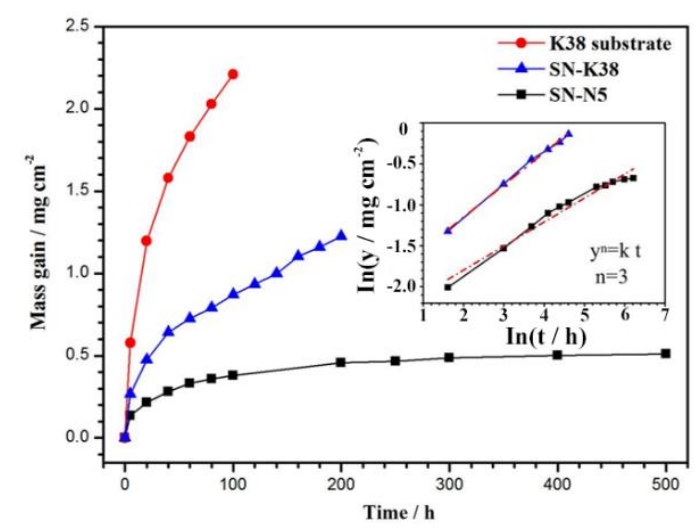

B

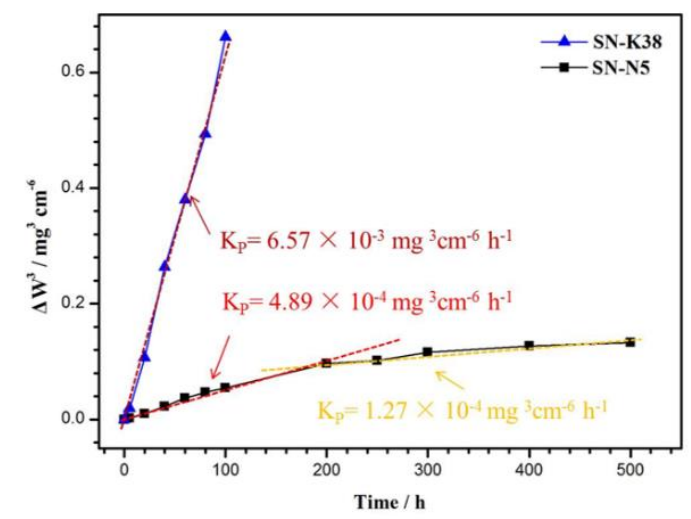

Figure 2. (A) Oxidation kinetics of superalloy substrate K38 and nanocrystalline coatings; (B) Function relationship between $\log (y)$ and $\log (t)$ was also plotted in $(\mathbf{A})$.

\subsection{Oxidation Behavior}

For the comparative study, the oxidation kinetics were divided into three periods $(0-100,100-200$, 200-500 h). The oxidation behavior of the K38 substrate alloy, SN-K38 and SN-N5 coatings were dissected as follows.

For the initial $100 \mathrm{~h}$, the phase constituents of the oxide scales formed on the substrate alloy and nanocrystalline coatings (SN-K38 and SN-N5) after oxidation at $1050^{\circ} \mathrm{C}$ in air are detected by XRD and shown in Figure 3. As shown in Figure 3A, the strongest peaks were corresponding to $\gamma$ and $\gamma^{\prime}$. Moreover, it was clearly seen that the oxide scale was composed of $\mathrm{Cr}_{2} \mathrm{O}_{3}$ and $\mathrm{TiO}_{2}$ for the superalloy $\mathrm{K} 38$. The oxide scale on the nanocrystalline coatings were mainly composed of $\alpha-\mathrm{Al}_{2} \mathrm{O}_{3}$. Weak peaks of $\theta-\mathrm{Al}_{2} \mathrm{O}_{3}$ were also detected within the XRD pattern of the coatings. Due to the phase peaks of SN-N5 formed in the XRD, the results were too weak to confirm; Figure 3B shows all the GI (grazing incidence)-XRD results of the $\mathrm{SN}-\mathrm{N} 5$ coatings for $100,200,500 \mathrm{~h}$ respectively. It is clearly to find the scale was composed of $\alpha-\mathrm{Al}_{2} \mathrm{O}_{3}$ and $\theta-\mathrm{Al}_{2} \mathrm{O}_{3}$ after $100 \mathrm{~h}$ oxidation at $1050{ }^{\circ} \mathrm{C}$. Figure 4 shows the surface morphologies of K38 alloy, SN-K38 and SN-N5 coatings after oxidation within $100 \mathrm{~h}$ at $1050{ }^{\circ} \mathrm{C}$. As shown in Figure 4A, multiple-slip spallation of the oxide was observed. It could be inferred that the substrate had suffered severe unstable oxidation from 0 to $100 \mathrm{~h}$. In addition, some porous oxides appeared on the surface of the alloy. With the help of XRD analysis and EDS results, there were $\mathrm{TiO}_{2}$ and $\mathrm{Cr}_{2} \mathrm{O}_{3}$ forming on the surface (as denoted by mark ' 1 ' and ' 2 ') of the $\mathrm{K} 38$ alloy. Table 4 shows all the chemical compositions of marks from 1 to 7 in Figure 4 via EDS. The corresponding cross-sectional morphologies of the substrate alloy and coatings after $100 \mathrm{~h}$ exposure at $1050{ }^{\circ} \mathrm{C}$ were shown in Figure 5. The K38 alloy exhibited a rough surface with many defects as large holes and internal oxidation beneath the external scales. Pores were also observed at the path of crack propagation. The surface microstructure of SN-K38 nanocrystalline coating was exhibited in Figure 4B. The oxide scale was largely flat except for some globular nodules. Anyway, no spallation occurred. Combined with the XRD results, it could be speculated that the main oxide was $\mathrm{TiO}_{2}$ at the globular nodule, while $\alpha-\mathrm{Al}_{2} \mathrm{O}_{3}$ at the flat area (as denoted by mark ' 3 ' and ' 4 '). From the cross-sectional morphology in Figure $5 \mathrm{~B}$, the oxide scale was uniform in $\mathrm{Al}_{2} \mathrm{O}_{3}$ with some contrast in bulging areas compared to lighter ones, which is consistent with Figure $4 \mathrm{~B}$ and Table 3. Slight internal oxidation was found in the coating beneath the $\mathrm{TiO}_{2}$, which leads to the final fracture of oxide scale in the mode of bulk spallation. For the SN-N5 nanocrystalline coating, its surface morphologies were shown in Figure 4C,D after 20 and $100 \mathrm{~h}$ oxidation, respectively. The oxide scale formed on the SN-N5 nanocrystalline coating was intact with a multi-flowered surface. The flower-like fields on the scale had grown wider in size and increased in amount along with the oxidation proceeds, and were composed only of aluminum oxides (as denoted by mark ' 5 ', ' 6 ' and ' 7 '). The scale was very thin, which was about less than $2 \mu \mathrm{m}$ as shown in Figure 5C. 
A

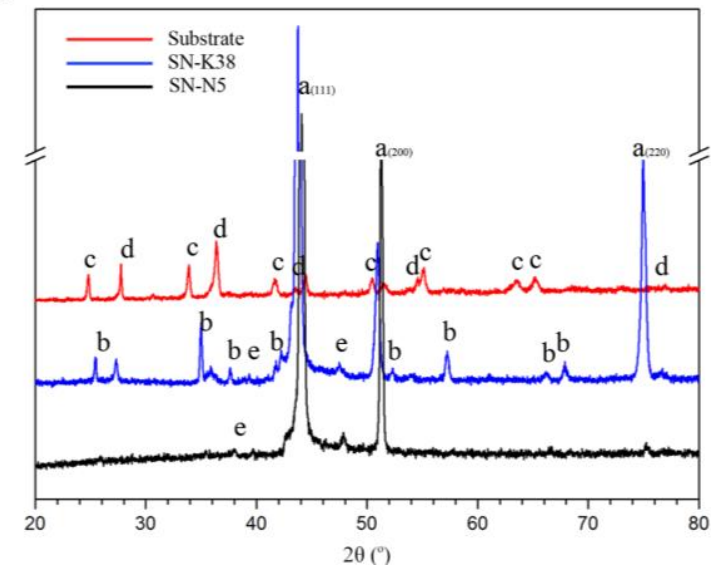

B

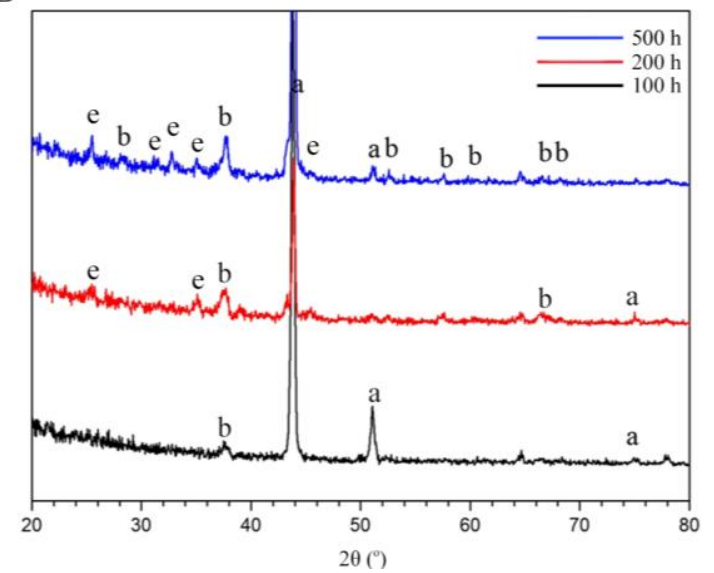

Figure 3. (A) X-ray diffraction (XRD) and (B) GI-XRD patterns of K38 substrate, $\mathrm{SN}-\mathrm{K} 38$ and SN-N5 coatings after oxidation at $1050{ }^{\circ} \mathrm{C}$ for $100 \mathrm{~h}\left(\mathrm{a} . \gamma / \gamma^{\prime}\right.$, b. $\alpha-\mathrm{Al}_{2} \mathrm{O}_{3}$, c. $\mathrm{Cr}_{2} \mathrm{O}_{3}$, d. $\mathrm{TiO}_{2}$, e. $\theta-\mathrm{Al}_{2} \mathrm{O}_{3}$ ).
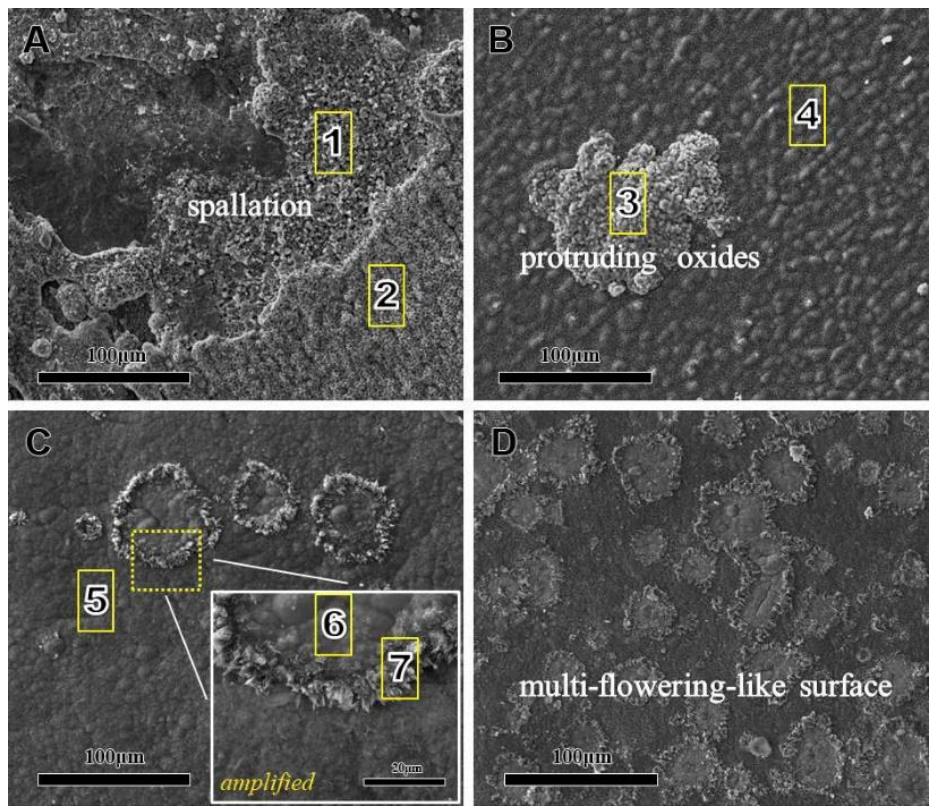

Figure 4. Surface morphologies after oxidation at $1050{ }^{\circ} \mathrm{C}$ in air: (A) K38 superalloy oxidized in air for $100 \mathrm{~h}$; (B) SN-K38 nanocrystalline coating oxidized in air for $100 \mathrm{~h}$; (C) SN-N5 nanocrystalline coatings after oxidized in air for $20 \mathrm{~h}$ and (D) $100 \mathrm{~h}$.

Table 4. Chemical composition (wt.\%) measured at surface of N5 nanocrystalline coating (denoted in Figure 4) by EDS.

\begin{tabular}{ccccccc}
\hline Element & $\mathbf{O}$ & $\mathbf{N i}$ & $\mathbf{C r}$ & $\mathbf{A l}$ & $\mathbf{T i}$ & Others \\
\hline 1 & 38.65 & 8.55 & 37.28 & 0.77 & 13.15 & 1.6 \\
2 & 39.26 & 0.71 & 31.14 & - & 27.64 & 1.25 \\
3 & 48.04 & 0.85 & 3.08 & 8.33 & 38.50 & 1.2 \\
4 & 47.74 & 1.30 & 2.19 & 43.32 & 5.45 & - \\
5 & 33.02 & 22.91 & 6.75 & 32.60 & - & 4.72 \\
6 & 38.44 & 10.59 & 4.18 & 39.49 & 1.1 & 6.2 \\
7 & 40.65 & 5.80 & 1.54 & 47.01 & - & 1.02 \\
\hline
\end{tabular}



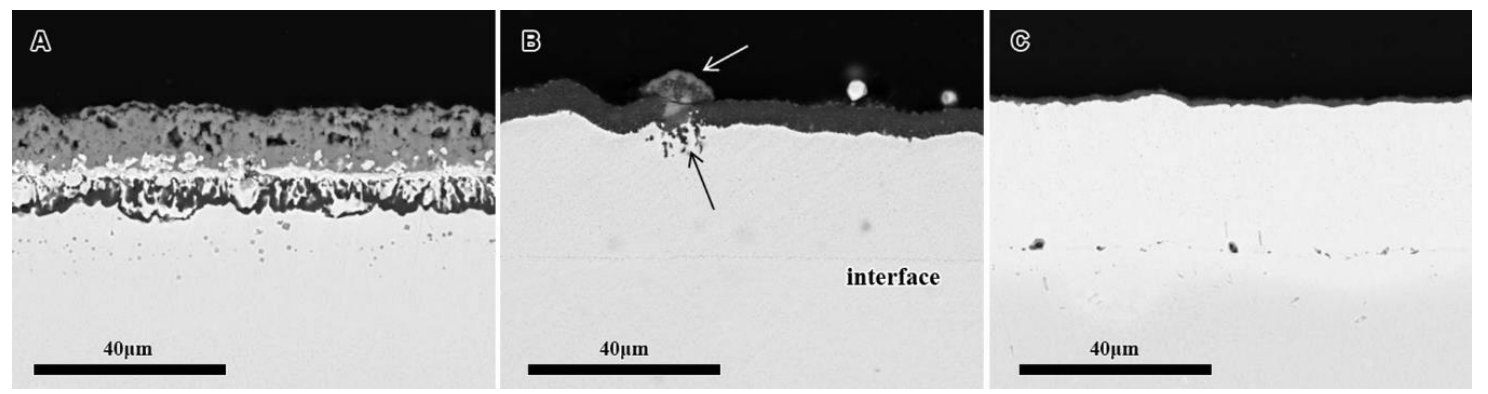

Figure 5. Cross-section morphologies of specimens in three groups after oxidation at $1050{ }^{\circ} \mathrm{C}$ for $100 \mathrm{~h}$ in air: (A) K38 superalloy; (B) SN-K38 nanocrystalline coating; (C) SN-N5 nanocrystalline coating.

With the oxidation prolonged to $200 \mathrm{~h}$, the microstructures of the SN-K38 and SN-N5 nanocrystalline coatings were investigated and are shown in Figure 6. It was clear that the normal SN-K38 nanocrystalline coating suffered severe oxidation instability, especially on the bulging part in Figure 6A. More detailed investigation of the phases formed on the oxide scales was possible by XRD and GI-XRD, and the results are shown in Figures $3 \mathrm{~B}$ and 7 for the two groups of nanocrystalline coatings, respectively. Combined with the cross-sectional microstructure in Figure 6B for the SN-K38 coating, the oxide scale was discontinuously formed and consists of dark $\alpha-\mathrm{Al}_{2} \mathrm{O}_{3}$ and gray $(\mathrm{Ni}, \mathrm{Co}) \mathrm{Al}_{2} \mathrm{O}_{4}$ spinels, which agrees well with the $\mathrm{XRD}$ results. Moreover, many $\mathrm{TiO}_{2}$ oxides were detected in the spallation area. Improved microstructure images could be observed for the SN-N5 nanocrystalline coating after $200 \mathrm{~h}$ oxidation at $1050^{\circ} \mathrm{C}$, as shown in Figure $6 \mathrm{C}, \mathrm{D}$. The alumina scale formed on the surface was thin and continuous. In addition, flowering-like fields, reaching $80 \mu \mathrm{m}$ wide, along with many micro-pores, could be observed on the oxide surface. The detailed information of the oxide scale was revealed in the amplified sights of Figure $6 C_{1}, C_{2}$. It should be noted that the so-called pores were not defective pores or ruptures. In fact, they were the edges of flower clusters of different oxides composed of two different types of aluminide oxide.
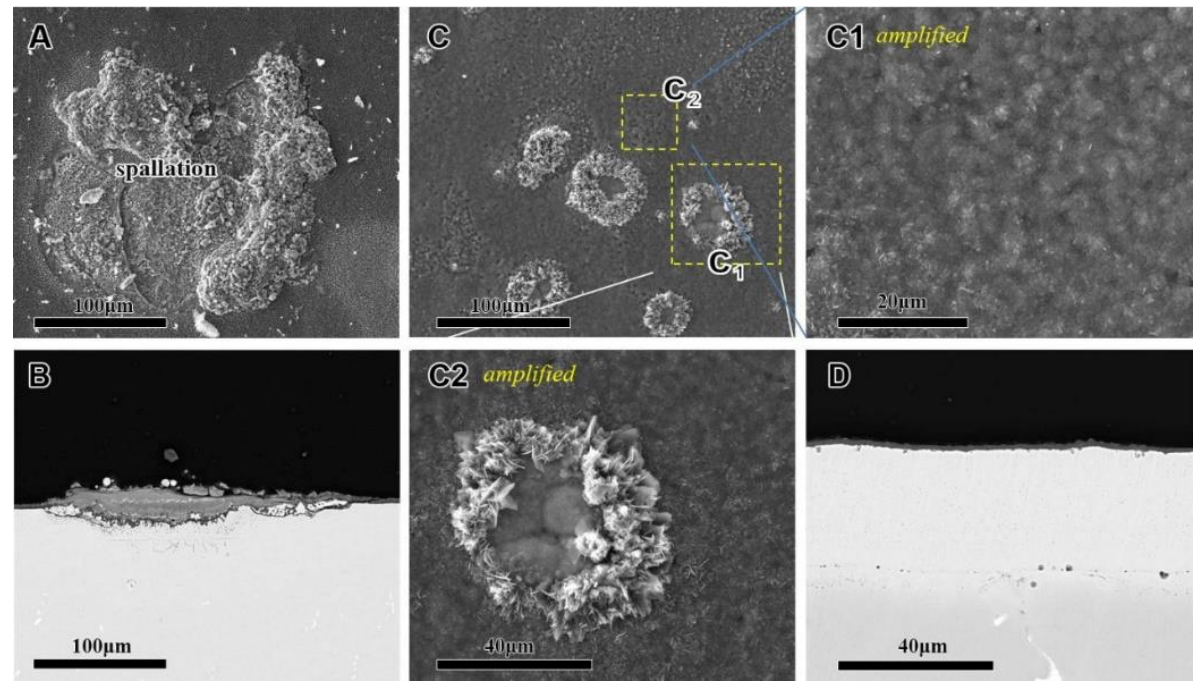

Figure 6. Microstructures of nanocrystalline coatings after oxidation at $1050{ }^{\circ} \mathrm{C}$ for $200 \mathrm{~h}$ : (A) surface and (B) cross-sectional morphologies of SN-K38 coating; (C) surface (amplified view in C and denoted as $\mathbf{C}_{\mathbf{1}}$ and $\mathbf{C}_{\mathbf{2}}$ ) and (D) cross-section morphologies of $\mathrm{SN}-\mathrm{K} 5$ coating. 


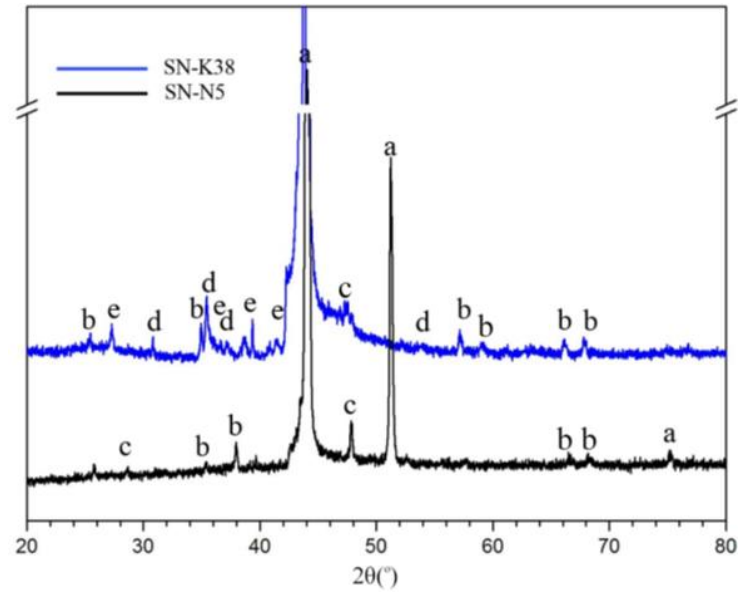

Figure 7. XRD patterns of nanocrystalline coatings after oxidation at $1050{ }^{\circ} \mathrm{C}$ for $200 \mathrm{~h}$ (a. $\gamma / \gamma^{\prime}$, b. $\alpha-\mathrm{Al}_{2} \mathrm{O}_{3}$, c. $\theta-\mathrm{Al}_{2} \mathrm{O}_{3}$, d. $\mathrm{Ni}_{2} \mathrm{CrO}_{4}$, e. $\mathrm{TiO}_{2}$ ).

The detailed microstructures of the SN-N5 nanocrystalline coating were conducted up to $500 \mathrm{~h}$, as exhibited in Figure 8. Furthermore, its oxide phases were almost the same as that oxidized after 100 and $200 \mathrm{~h}$, as shown in Figure 9. Combined with the XRD and GI-XRD results, the oxide scale on SN-N5 coating was composed mainly of $\alpha-\mathrm{Al}_{2} \mathrm{O}_{3}$ and $\theta-\mathrm{Al}_{2} \mathrm{O}_{3}$. After oxidation for $500 \mathrm{~h}$, the scale still bonded well to the underlying SN-N5 coating. It could be confirmed that the SN-N5 coating produced not only higher oxidation resistance but also higher spallation resistance than the SN-K38 coating.
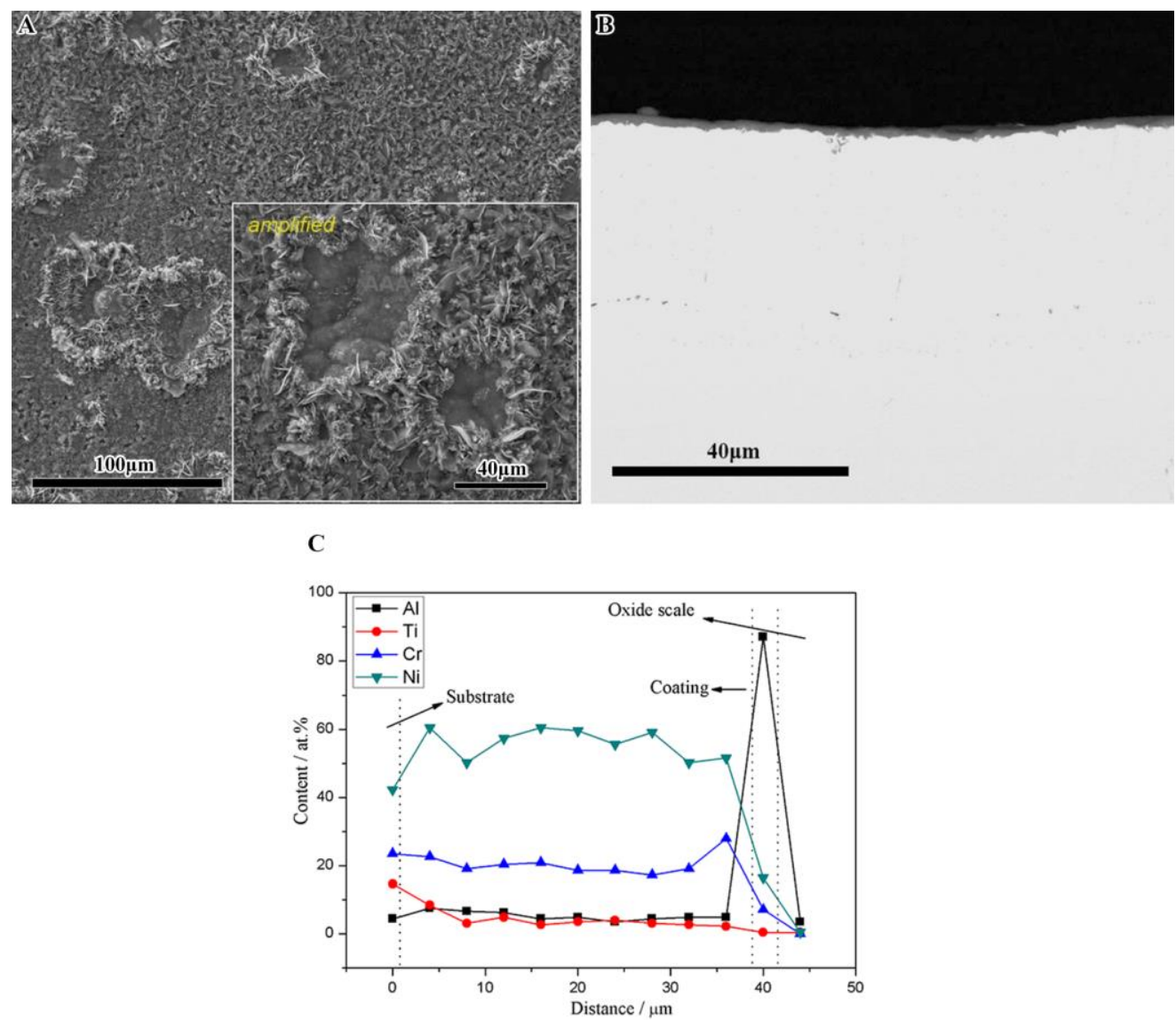

Figure 8. Microstructures of SN-N5 nanocrystalline coatings after oxidation at $1050{ }^{\circ} \mathrm{C}$ for $500 \mathrm{~h}$ : (A)surface and (B) cross-section morphologies; (C) the elemental distribution in depth by EDS line-scanning at the interface plot in (B). 


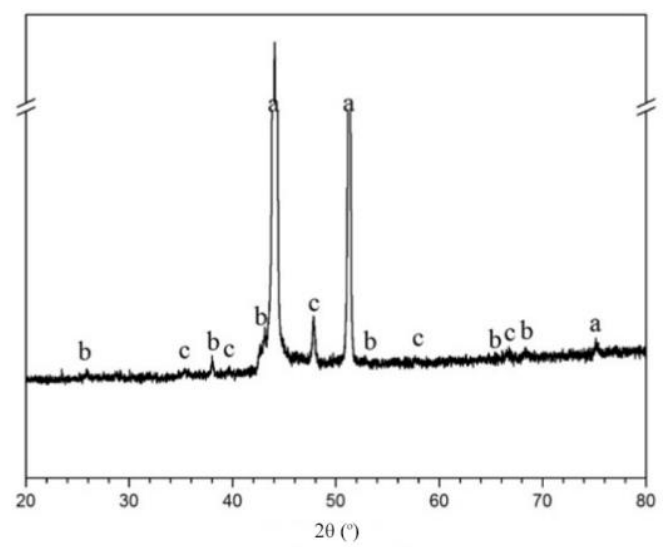

Figure 9. $\mathrm{XRD}$ patterns of SN-N5 nanocrystalline coatings after oxidation at $1050{ }^{\circ} \mathrm{C}$ for $500 \mathrm{~h}$ (a. $\gamma / \gamma^{\prime}$, b. $\alpha-\mathrm{Al}_{2} \mathrm{O}_{3}$, c. $\theta-\mathrm{Al}_{2} \mathrm{O}_{3}$ ).

\subsection{Influence of the Elements Interdiffusion}

Chemical potential is the one of the most important factors causing serious elements interdiffusion between the substrate alloy and sub-layer coating [38]. Nanocrystalline coatings attracted great interest for improving the negative influence that avoids the formation of TCP induced by elements interdiffusion. In this study, the two groups of nanocrystalline coatings had essential differences in designed composition. The SN-K38 coating had the nominal composition of the substrate alloy as per the designed nanocrystalline. However, the SN-N5 coating was modified with comparably differences of element contents with substrate K38 alloy. So that, the interdiffusion behavior of SN-N5 coating was careful studied at the interface between substrate alloy and coating as follows.

From the cross-sectional view of the as-deposited SN-N5 coating, some spots and voids were found at the alloy/coating interface. It was firstly induced by a sand-blasting process before the coating was deposited. As shown in Figures 5B and 6B, the SN-K38 coating had a relatively flat interface and the sand-blasting had already disappeared. However, obvious voids and rough interfaces were observed by the cross-sectional images in Figures 5C and 6C for the SN-N5 coating. Notably, the number of voids and roughness dramatically decreased as the oxidation processed, and there had almost no difference with that occurred on the SN-K38 coating. To obtain the specific information about element changing in contents on the SN-N5 coating, the elements' line-scanning curves were gathered by EDS with statistics and are shown in Figure 8C for $500 \mathrm{~h}$. No notable elemental differences were observed.

Figures 10 and 11 clearly show the TEM microstructures of the SN-N5 coating after oxidation at $1050{ }^{\circ} \mathrm{C}$ in air for 100 and $500 \mathrm{~h}$, respectively. As observed on the TEM-EDS results in Figure 10, the bright-field image and EDS elements map for most constituents and corresponding diffraction patterns represented the microscopic changes on the interface of substrate alloy and coatings after $100 \mathrm{~h}$ oxidation at $1050{ }^{\circ} \mathrm{C}$. Some micro-voids were observed on the interface, which is consistent with the cross-sectional morphologies. Most of the elements were uniformly distribute beyond the coating except for the chromium. With the help of the EDS analysis and selected area electron diffraction (SAED) patterns analysis, there had $\gamma$-Ni in the $\mathrm{Cr}$ depleted region and $\gamma-\mathrm{Ni} / \alpha-\mathrm{Cr}$ in the other areas. Besides, the original $\gamma / \gamma^{\prime}$ structure of the superalloy K38 was found below the interdiffusion zone by about $4-5 \mu \mathrm{m}$. As the oxidation process prolonged for $500 \mathrm{~h}$, the bright-field image, EDS elements map for most constituents and corresponding diffraction patterns represented the microscopic changes on the interface of substrate alloy and coating were shown in Figure 11. A similar element mapping distribution was represented as uniform as $100 \mathrm{~h}$ for the main components. However, a great difference in the grain size of the substrate alloy was found after $500 \mathrm{~h}$. The $\mathrm{Cr}$ depleted area became more instinct and the distance of interdiffusion zone came to about $5 \mu \mathrm{m}$. Most of all, the constituent and the phase evolution did not seem to be serious after such long-term oxidation at $1050{ }^{\circ} \mathrm{C}$. 


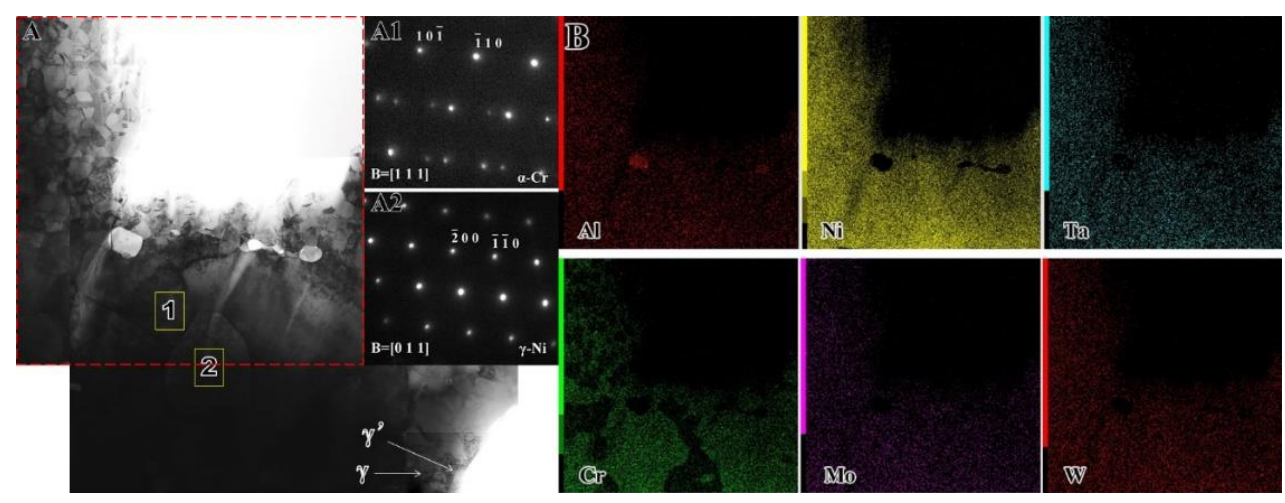

Figure 10. TEM bright field image (A) and elemental maps (B) displayed the microstructure of the interface between SN-N5 coating/substrate after oxidation at $1050^{\circ} \mathrm{C}$ in air for $100 \mathrm{~h}$. (A1,A2) were the SAED patterns obtained at the area denoted as 1 and 2 in (A).

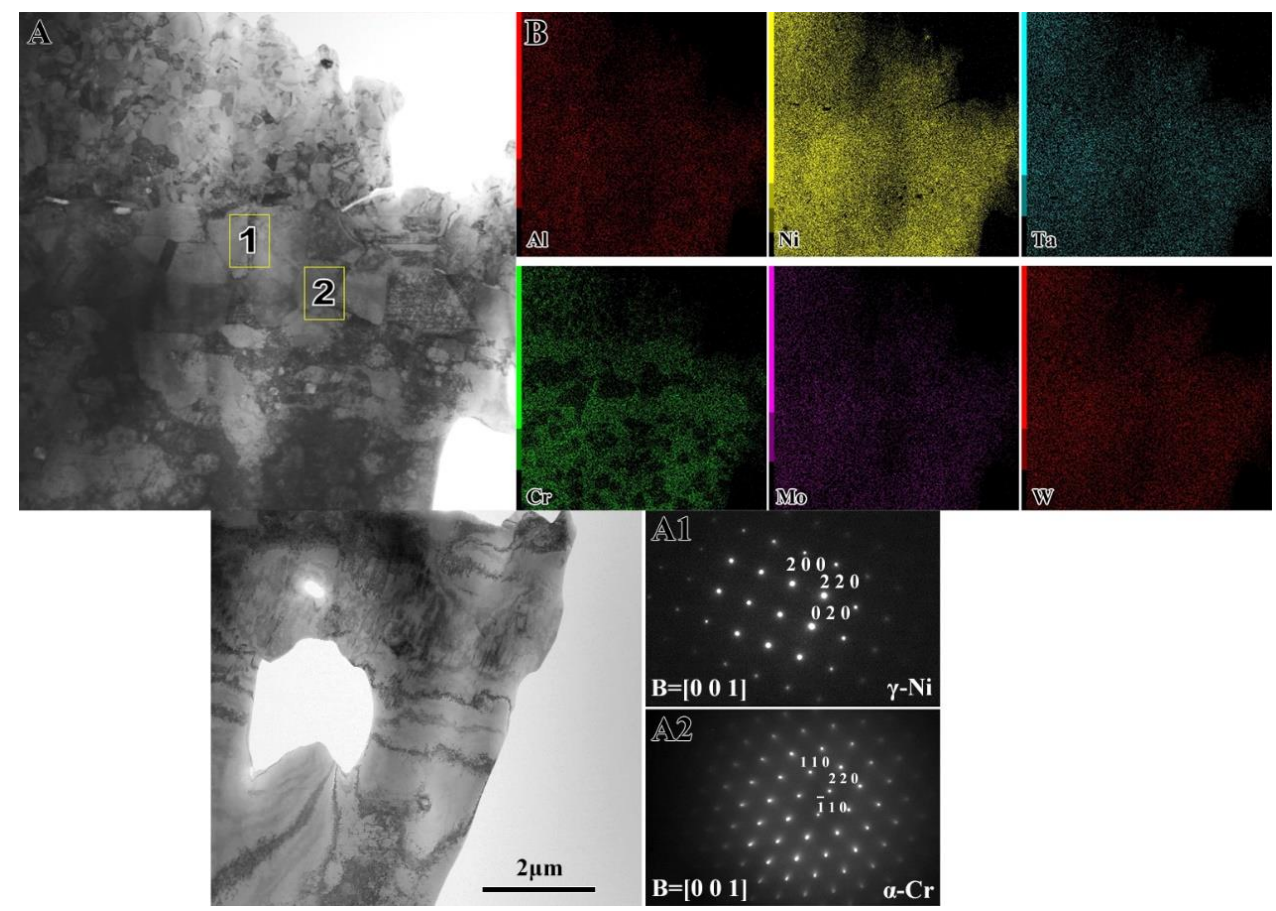

Figure 11. TEM bright field image (A) and elemental maps (B) displayed the microstructure of the interface between SN-N5 coating/substrate after oxidation at $1050^{\circ} \mathrm{C}$ in air for $500 \mathrm{~h}$. (A1,A2) were the SAED patterns obtained at the areas denoted as 1 and 2 in (A).

\section{Discussion}

\subsection{Study on Oxidation Failure Behavior}

Grain boundaries are short paths for $\mathrm{Al}$ or $\mathrm{Cr}$ diffusion in the alumina-forming and chromia-forming alloys [32]. The critical concentration of elements for transition from internal to external oxidation would be reduced, for the diffusivity of increasing elements [31]. Thus, the chemical composition and their microstructures, especially the refined grain size that made the alloys exhibits good oxidation resistance during serving at temperature environment. Compared to the cast superalloy $\mathrm{K} 38$, there are a number of grain boundaries in the sputtered nanocrystalline coating, which promotes the selective oxidation of Al. For $1050{ }^{\circ} \mathrm{C}$ oxidation, the oxides formed on the substrate were mainly of $\mathrm{Cr}_{2} \mathrm{O}_{3}$ and $\mathrm{TiO}_{2}$, while they were $\mathrm{Al}_{2} \mathrm{O}_{3}$ on the nanocrystalline coatings. Lou et al. [36] reported that an alloy with a $\mathrm{Cr} / \mathrm{Al}$ ratio (in weight) of more than 4 belongs to the chromia-forming group. In this study, the $\mathrm{Cr} / \mathrm{Al}$ ratio in alloy $\mathrm{K} 38$ is a little higher than 4 . Therefore, the oxidation resistance of the 
$\mathrm{K} 38$ alloy substrate based on the chromium form on the surface of the specimens. However, due to the $\mathrm{CrO}_{3}$ having a kind of unstable oxidation when the temperature was at $1050{ }^{\circ} \mathrm{C}$, the protective capacity of chromium was limited. Thus, the scale forms on the substrate alloy tend to spall and the continuous spallation lead to accelerate consumption of chromia in the alloy. Meanwhile, the other component elements in the K38 alloy precipitate rapidly and substantially from the matrix phase and participated in the oxidation reaction. Therefore, the kinetics almost grow in linear law and enormous defects as voids and spallation come out during oxidation at $1050{ }^{\circ} \mathrm{C}$ for $100 \mathrm{~h}$ (Figures 2 and $4 \mathrm{~A}$ ).

The oxidation resistance of alloys are in connection with the formation of protective scales on the surface of alloys and coatings. In addition, the active component elements in the alloy usually affect the process in forming the oxide scale. For example, it had been reported by Pint [39] and Guo $[8,40]$ that the addition of $\mathrm{Y}, \mathrm{Zr}, \mathrm{Ce}, \mathrm{La}$ and $\mathrm{Hf}$ could have significant effects on the oxidation behavior of alumina-forming alloys and coatings. The two most important effects are improving scale adhesion and reducing scale growth rate. Furthermore, some refractory elements such as Ta and Ti often have higher activity in segregating at the boundaries of $\alpha-\mathrm{Al}_{2} \mathrm{O}_{3}$ which increase the serving temperature [31,41]. For segregation of Ta, it transferred the growth mode of alumina scale, i.e., from equiaxed to columnar grains. However, its excessive segregation will cause the formation of a large amount of less-protective tantalum oxides. As a result, in the nanocrystalline coatings, some severe refractory elements' segregation at scale exhibit a negative effect on oxidation resistance. In this study, a large amount of titanium oxides is distributed in the alumina scale and precipitated on the surface of the scale (Figures $5 \mathrm{~B}$ and $6 \mathrm{~B}$ ), which builds a bridge for tantalum diffusion from the nanocrystalline coating to the outer oxide scale. It has a great influence on decreasing the purity of the oxide scale and the oxidation resistance of the coating, which exhibits as the rapid growth of nonproductive oxides and the expansion and rupture of the oxide scale. Consecutively, it is found that Ti segregation affects as well the spalling mode of oxide scale developed on the nanocrystalline coating after $200 \mathrm{~h}$ oxidation.

\subsection{Oxidation Resistance of the Nanocrystalline Coatings}

The oxidation resistance has significantly improved, by sputtering, the nanocrystalline coatings and the protective alumina scales formed on the surface of the specimens. The domination of oxidation process was the diffusion of active species along the numerous grain boundaries. And, it was an important factor that reactive species, i.e., alumina or chromium, have priority in forming an oxide scale. This is due to the lower standard free energy of alumina formation, which compared with chromia. Furthermore, the mobility of alumina is faster than that of chromium at grain boundaries. Since the nanocrystalline coating is a columnar crystal structure, which size is less than $100 \mathrm{~nm}$, numerous grain boundaries facilitate the diffusion of aluminum to the surface and provide nucleation sites for oxides. Hence, in the initial stage of oxidation, continuous thin $\mathrm{Al}_{2} \mathrm{O}_{3}$ scale would form on the outer surface.The scale forming on the SN-N5 coating is pure and thin after oxidation for $500 \mathrm{~h}$, which exhibited the best performance on protecting the alloy $\mathrm{K} 38$ from invalidation in a severe environment. In our pervious study, the normal nanocrystalline N5 coating was designed as the same amount of Ta on weight as the single-crystal superalloy N5 [31,32]. The tantalum moves along the grain boundaries following the gradient of oxygen potential, and finally is partly oxidized at the middle of the oxide scale or scale surface. Recently, our working emphasis has considered how to suppress the active elements such as Ta or Ti from outward movement to the oxide scale. By contrast with the results of that on the SN-K38 coating, there have no indication that the scale on SN-N5 coating is affected by $\mathrm{Ti}$, and ignore the influence of Ta. This is due to the fact that $\mathrm{Ti}$ is inhibited and hardly diffused out from the matrix phase to the oxide/coating interface for nucleation. According to Wagner's theory, the critical solute concentration required for the transition from internal to external oxidation has been expressed as:

$$
N_{B}=\left(\frac{\pi g^{*} N_{O} D_{O} V_{M}}{2 D_{B} V_{O X}}\right)^{1 / 2}
$$


where $N_{O} D_{O}$ is the oxygen permeability in alloy, $D_{B}$ is the solute diffusivity, $g^{*}$ is a factor determined by the volume fraction of oxide required for the transition, and $V_{M}$ and $V_{O X}$ are molar volumes of the alloy and oxide, respectively. Equation (2) can be simplified as:

$$
N_{B} \propto D_{B}^{-1 / 2}
$$

Therefore, the solute content require for the external scale formation increasing with the molar volumes of the alloy components. The results show that the refractory elements cannot reach their critical value for the formation of its oxide. Moreover, the atom radius of the refractory element was so large that it was difficult to diffuse either from inside out or from outside to inside. Thus, the $D_{B}$ value was always limited to a certain range both for the Ti and Ta on the SN-N5 coating. Last but not least, the SN-N5 showed a relatively lower kinetic on mass gain among the three groups. It could be found the microstructure for $500 \mathrm{~h}$ oxidation, the oxide scale formed on the coating was extremely thin. Based on our pervious study, selective oxidation of Al took place initially according to the Ellingham diagram which indicated higher affinity of $\mathrm{Al}$ to $\mathrm{O}$ than that of $\mathrm{Ta}, \mathrm{Cr}$ or $\mathrm{Ni}$ to $\mathrm{O}$. After the consumption of $\mathrm{Al}$, Ta would be oxidized. As the consumption process lasts for such a long period for the alumina in the SN-N5 coating, the origin single $\gamma$ phase would slowly transform to dual phases $\left(\gamma / \gamma^{\prime}\right)$ to seek thermodynamic equilibrium. Due to the low content of $\mathrm{Al}$ and so many defects in the nanocrystalline coating, most Ta always precipitate out from the $\gamma$ solution and locate at the $\mathrm{Al}$ site in the $\gamma^{\prime}-\mathrm{Ni}_{3} \mathrm{Al}$ structure to form Ta-rich $\gamma^{\prime}$ phases [31]. Based on the phase transformation having earlier been retarded in the initial oxidation process by kinetics, the diffusion of Ta is hard to dissolve out and be oxidized.

A flower-like morphology was found after oxidation on the surface of the SN-N5 coating. Notably, the phenomenon became even obvious as the oxidation duration was prolonged, and the surface appeared to coarsen significantly before $\alpha-\mathrm{Al}_{2} \mathrm{O}_{3}$ formed after oxidation for $20 \mathrm{~h}$. In fact, this was induced by the phase transformation of the aluminum. The transformation from $\theta-\mathrm{Al}_{2} \mathrm{O}_{3}$ to $\alpha-\mathrm{Al}_{2} \mathrm{O}_{3}$ involves a change in the oxygen sublattice from cubic to hexagonal close packing (ccp $\rightarrow h c p)$ and generally occurs above $1000-1200^{\circ} \mathrm{C}[42,43]$. Although the $\alpha-\mathrm{Al}_{2} \mathrm{O}_{3}$ transformation has been reported to occur by two modes of diffusional nucleation and shear nucleation, the $\alpha-\mathrm{Al}_{2} \mathrm{O}_{3}$ nucleation mechanism within single $\theta-\mathrm{Al}_{2} \mathrm{O}_{3}$ crystals behaved a little differently in this study. The EDS analysis and the XRD results show the surface scale was almost flat and mainly composed of $\alpha-\mathrm{Al}_{2} \mathrm{O}_{3}$ after $20 \mathrm{~h}$ oxidation, which exhibited the aluminum transformation process in a normal mode. After that, a small amount of $\theta-\mathrm{Al}_{2} \mathrm{O}_{3}$ grew outside the surface and the peaks of $\theta-\mathrm{Al}_{2} \mathrm{O}_{3}$ increased significantly until $500 \mathrm{~h}$. The newly formed $\theta-\mathrm{Al}_{2} \mathrm{O}_{3}$ grew in the intrinsic form of $\alpha-\mathrm{Al}_{2} \mathrm{O}_{3}$. It can be speculated that the $\theta-\mathrm{Al}_{2} \mathrm{O}_{3}$ is a ' $P$ ' type outer growth oxide, and the speed of its $\mathrm{Al}$ atoms diffuse out and generate on the original surface of $\alpha-\mathrm{Al}_{2} \mathrm{O}_{3}$ quite slowly. The grain size of the newly formed aluminum will become larger and more difficult in the transformation of the $\alpha-\mathrm{Al}_{2} \mathrm{O}_{3}$. The high degree of atomic freedom of the grain boundary and other defects is not conducive to the coordinated motion with other atoms. Therefore, the increase of grain boundary after refinement is not conducive to the process of edge cutting nucleation. In some areas, it is possible to achieve the critical size of the phase change and cut the edge under the action of the internal stress of the oxide film.

\subsection{Interdiffusion between the Substrate and SN-N5 Coating}

In the case of MCrAlY coatings as in our studies, the continuous inward diffusion of $\mathrm{Al}$ and outward diffusion of Ni promoted the $\gamma$ to $\gamma^{\prime}$ phase transformation in the superalloy, destroyed the $\gamma / \gamma^{\prime}$ structure and impelled the precipitation of refractory elements from $\gamma$ phase along with the high temperature oxidation [44]. This will reduce the oxidation resistance of the protective coating and deteriorate the mechanical properties of the coating system due to the TCP phase of $\mathrm{Cr}$ and the refractory elements' reaction products being precipitated as well as the detrimental SRZ formed. However, TCP phases are not observed in the SN-N5 coatings even after suffered long-term isothermal 
oxidation at $1050^{\circ} \mathrm{C}$ for $500 \mathrm{~h}$. Actually, interdiffusion has indeed occurred and been observed after initial oxidation by the microstructure images, where the change of contrast with backscatter mode in the substrate is internal and at the interface of the SN-N5 coating and substrate alloy. In details, SN-N5 coating appears a strip of contrast change interval at the surface of K38 alloy by SEM in the scatter mode. In fact, these are induced by the differences in element content. For instance, Ni was composed of $66 \mathrm{wt} . \%$ in the SN-N5 coating but $61 \mathrm{wt} . \%$ in K38 alloy, thus the interdiffusion behavior of Ni might occur inside the substrate alloy. As the oxidation process prolongs to $500 \mathrm{~h}$, the distribution of all the elements became even more uniform, so that the contrast change was consistent. With the help of high-power TEM images, the results showed that the interdiffusion zone extends about 4-5 $\mu \mathrm{m}$ to the end of this experiment. In our previous studies, after long-term high temperature oxidation, there was a certain threshold for the diffusion of the coating or a certain thickness of coating/substrate system, and it can be inferred that the depth induced by elements diffusion, such as $\mathrm{Ni}$ and $\mathrm{Al}$ had reached its limit. For example, the limiting diffusion region of a system of $45 \mu \mathrm{m}$ NiCrAlY coating on the single-crystal superalloy N5 was about $78 \mu \mathrm{m}$ at most, when oxidation occurred at $1000{ }^{\circ} \mathrm{C}$ [24]. Therefore, it was believed that the diffusion movement for a system of $33 \mu \mathrm{m}$ SN-N5 coating on the cast alloy K38 was basically completed within $500 \mathrm{~h}$ oxidation at $1050^{\circ} \mathrm{C}$.

The formation of the TCP phase is the most direct microstructure evidence to judge whether it will affect the mechanical properties of the matrix alloy or not [25]. Due to the brittleness of the TCP phase and its needle-like shape, fatigue cracks would initiate easily at the sharp corner under thermal or force cycling. After $100 \mathrm{~h}$ oxidation, the TEM bright field image of the SN-N5 coating shows that the structure changes obviously at the surface of the substrate, where phase constitutions have almost fully transformed from $\gamma / \gamma^{\prime}$ phases to a single $\gamma$ phase due to the elemental depletion. Moreover, the grain size in the newly $\gamma$ phase becomes smaller gradually along with the oxidation process to $500 \mathrm{~h}$. We cannot find any element segregation by the surface distribution through EDS analysis, except for Cr. The distribution of SAED diffraction patterns gradually decreases from large to small, and the main components of SAED diffraction patterns are $\alpha$-Cr phase and common $\gamma$ phase. Therefore, no segregation of elements is found.

The interdiffusion always breaks the phase equilibrium and decreases the mechanical properties of the substrate alloy. However, this behavior can promote the interface being bonded well to some extent. In this study, the composition of the elements between the N5 and K38 alloys have a distinct difference in content. Therefore, the diffusion behavior of the SN-N5 coating is more significant than that on the SN-K38 coating, and some voids appear at the coating/substrate interface after oxidation for $100 \mathrm{~h}$. Nucleation and the growth of voids can be observed in every externally grown oxide scale. When the voids are widely spaced and remain small, they have little effect on scale adhesion. It is precisely because of the continuous diffusion process, these interface defects will gradually regrow with the extension of oxidation duration. Therefore, the interdiffusion will also strengthen the interface integration efficiency.

\section{Conclusions}

From the above study, the following conclusions can be drawn:

(1) A new designed nanocrystalline coating was prepared on the superalloy K38. No notable diffusion of elements was observed at the interface between the cast alloy K38 and its sputtering nanocrystalline coating after oxidation. No TCP phases were found at the interfacial area even after exposure at $1050^{\circ} \mathrm{C}$ for as long as $500 \mathrm{~h}$.

(2) The sputtering nanocrystalline coatings enhanced the oxidation resistance of the cast superalloy $\mathrm{K} 38$ at $1050^{\circ} \mathrm{C}$ for $100 \mathrm{~h}$. However, the SN-K38 nanocrystalline coating did not maintain good oxidation resistance when the oxidation time was extended to $200 \mathrm{~h}$. The oxide scale gained weight rapidly and there is a large area of spalling on the surface.

(3) The sputtered SN-N5 nanocrystalline coating enhanced both the oxidation resistance and spallation resistance of the superalloy substrate at $1050{ }^{\circ} \mathrm{C}$. 
Author Contributions: Conceptualization, J.W., W.S. and M.C.; Methodology, J.W., B.M., L.Y. and M.C.; Investigation, B.M. and J.W.; Data curation, B.M., W.S. and L.Y.; Writing-original draft preparation, J.W. and M.C.; Writing-review and editing, J.W., B.M., L.Y., M.C. and F.W.; Visualization, J.W., L.Y., M.C. and F.W. All authors have read and agreed to the published version of the manuscript.

Funding: This research was funded by the fundamental Research Funds for the Central Universities (No. N170203008), the National Natural Science Foundation of China (No. 51671053 and No. 51801021), by the Ministry of Industry and Information Technology Project (No. MJ-2017-J-99), and by the Science and Technology Project of China Huaneng Group (HNKJ20-H43).

Conflicts of Interest: The authors declare no conflict of interest.

\section{References}

1. Clarke, D.R.; Levi, C.G. Materials design for the next generation thermal barrier coatings. Annu. Rev. Mater. Res. 2003, 33, 383-417. [CrossRef]

2. Goward, G.W. Progress in coatings for gas turbine airfoils. Surf. Coat. Technol. 1998, 108, 73-79. [CrossRef]

3. Sengupta, A.; Putatunda, S.K.; Bartosiewicz, L.; Hangas, J.; Nailos, P.J.; Peputapeck, M.; Alberts, F.E. Tensile behavior of a new single-crystal nickel-based superalloy (CMSX-4) at room and elevated temperatures. J. Mater. Eng. Perform. 1994, 3, 73-81. [CrossRef]

4. Bond, S.D.; Martin, J.W. Surface recrystallization in a single crystal nickel-based superalloy. J. Mater. Sci. 1984, 19, 3867-3872. [CrossRef]

5. Gong, S.; Sun, Y.; Jin, L.; Su, Z. Experimental study on fabricating micro-holes in DD5 single-crystal nickel-based superalloy using electrical discharge drilling. Arch. Civ. Mech. Eng. 2020, 20, 1-16. [CrossRef]

6. Yan, H.; Tian, S.; Zhao, G.; Zhang, S. Creep damage of a high Mo single crystal nickel-based superalloy. Mater. High Temp. 2020, 37, 139-144. [CrossRef]

7. Tu, X.; Peng, H.; Zheng, L.; Qi, W.; He, J.; Guo, H.; Gong, S. Oxidation and microstructure evolution of Al-Si coated $\mathrm{Ni}_{3} \mathrm{Al}$ based single crystal superalloy with high Mo content. Appl. Surf. Sci. 2015, 325, $20-26$. [CrossRef]

8. Guo, C.; Wang, W.; Cheng, Y.; Zhu, S.; Wang, F. Yttria partially stabilised zirconia as diffusion barrier between NiCrAlY and Ni-base single crystal Rene N5 superalloy. Corros. Sci. 2015, 94, 122-128. [CrossRef]

9. Ren, P.; Zhu, S.; Wang, F. Characterization and oxidation behavior of a sputtered nanocomposite $\mathrm{Ni}+\mathrm{CrAlYSiHfN}$ coating. Corrosion 2015, 71, 523-535. [CrossRef]

10. Yang, Y.F.; Ren, P.; Bao, Z.B.; Zhu, S.L.; Wang, F.H.; Li, W. Microstructure and cyclic oxidation of a Hf-doped (Ni,Pt)Al coating for single-crystal superalloys. J. Mater. Sci. 2020, 55, 11687-11700. [CrossRef]

11. Hu, Y.; Cai, C.; Wang, Y.; Yu, H.; Zhou, Y.; Zhou, G. YSZ/NiCrAlY interface oxidation of APS thermal barrier coatings. Corros. Sci. 2018, 142, 22-30. [CrossRef]

12. Yang, S.; Wang, Y.; Chen, M.; Yang, L.; Wang, J.; Zhu, S.; Wang, F. Oxidation behavior of Al/Y co-modified nanocrystalline coatings with different $\mathrm{Al}$ content on a nickel-based single-crystal superalloy. Corros. Sci. 2020, 170, 108700. [CrossRef]

13. Li, W.; Zhu, S.; Chen, M.; Wang, C. Development of an oxidation resistant glass-ceramic compositecoating on Ti-47Al-2Cr-2Nb alloy. Appl. Surf. Sci. 2014, 292, 583-590. [CrossRef]

14. Chen, Y.; Zhao, X.; Xiao, P. Effect of microstructure on early oxidation of MCrAlY coatings. Acta Mater. 2018, 159, 150-162. [CrossRef]

15. Richer, P.; Yandouzi, M.; Beauvais, L.; Jodoin, B. Oxidation behaviour of CoNiCrAlY bond coats produced by plasma, HVOF and cold gas dynamic spraying. Surf. Coat. Technol. 2010, 204, 3962-3974. [CrossRef]

16. Chen, Y.; Zhao, X.; Dang, Y.; Xiao, P.; Curry, N.; Markocsan, N.; Nylén, P. Characterization and understanding of residual stresses in a NiCoCrAlY bond coat for thermal barrier coating application. Acta Mater. 2015, 94, 1-14. [CrossRef]

17. Chen, Y.; Xiao, X.; Bai, M.; Chandio, A.; Wu, R.; Xiao, P. Effect of platinum addition on oxidation behaviour of $\gamma / \gamma^{\prime}$ nickel aluminide. Acta Mater. 2015, 86, 319-330. [CrossRef]

18. Haynes, J.A.; Pint, B.A.; Zhang, Y.; Wright, I.G. Comparison of the cyclic oxidation behavior of $\beta-\mathrm{NiAl}$, $\beta$-NiPtAl and $\gamma-\gamma^{\prime} \mathrm{NiPtAl}$ coatings on various superalloys. Surf. Coat. Technol. 2007, 202, 730-734. [CrossRef]

19. Yang, L.; Chen, M.; Cheng, Y.; Wang, J.; Liu, L.; Zhu, S.; Wang, F. Effects of surface finish of single crystal superalloy substrate on cyclicthermal oxidation of its nanocrystalline coating. Corros. Sci. 2016, 111, 313-324. [CrossRef] 
20. Tolpygo, V.K.; Clarke, D.R. On the rumpling mechanism in nickel-aluminide coatings: Part II. Characterization of surface undulations and bond coat swelling. Acta Mater. 2004, 52, 5129-5141. [CrossRef]

21. Ren, P.; Zhu, S.; Wang, F. Microstructure and oxidation behavior of a Ni+CrAlYSiHfN/AlN multilayer coating fabricated by reactive magnetron sputtering. Corros. Sci. 2016, 104, 197-206. [CrossRef]

22. Yang, Y.; Yao, H.; Bao, Z.; Ren, P.; Li, W. Modification of NiCoCrAlY with Pt: Part I. Effect of Pt depositing location and cyclic oxidation performance. J. Mater. Sci. Technol. 2019, 35, 341-349. [CrossRef]

23. Zhu, L.; Zhu, S.; Wang, F. Preparation and oxidation behaviour of nanocrystalline Ni+CrAlYSiN composite coating with AlN diffusion barrier on Ni-based superalloy K417. Corros. Sci. 2012, 60, 265-274. [CrossRef]

24. Wang, J.; Chen, M.; Yang, L.; Zhu, S.; Wang, F. Comparative study of oxidation and interdiffusion behavior of AIP NiCrAlY and sputtered nanocrystalline coatings on a nickel-based single-crystal superalloy. Corros. Sci. 2015, 98, 530-540. [CrossRef]

25. Yang, L.; Chen, M.; Wang, J.; Qiao, Y.; Guo, P.; Zhu, S.; Wang, F. Microstructure and composition evolution of a single-crystal superalloy caused by elements interdiffusion with an overlay NiCrAlY coating on oxidation. J. Mater. Sci. Technol. 2020, 45, 49-58. [CrossRef]

26. Yang, L.; Chen, M.; Wang, J.; Bao, Z.; Zhu, S.; Wang, F. Oxidation of duplex coatings with different thickness ratio of the inner nanocrystalline layer to the outer NiCrAlY one. Corros. Sci. 2018, 143, 136-147. [CrossRef]

27. Yang, L.; Chen, M.; Wang, J.; Bao, Z.; Zhu, S.; Wang, F. Diffusion of Ta and its influence on oxidation behavior of nanocrystalline coatings with different Ta, Y and Al contents. Corros. Sci. 2017, 126, 344-355. [CrossRef]

28. Yang, L.; Chen, M.; Wang, J.; Zhu, S.; Wang, F. A duplex nanocrystalline coating for high-temperature applications on single-crystal superalloy. Corros. Sci. 2016, 102, 72-83. [CrossRef]

29. Jiang, W.; Yu, P.; Wang, W.; Zhu, S.; Wang, F. Hot Corrosion behavior of sputtered nanocrystalline coating with yttrium addition at $900^{\circ} \mathrm{C}$. Materials 2014, 7, 2882-2889. [CrossRef]

30. Wang, J.; Chen, M.; Cheng, Y.; Yang, L.; Bao, Z.; Liu, L.; Zhu, S.; Wang, F. Hot corrosion of arc ion plating NiCrAlY and sputtered nanocrystalline coatings on a nickel-based single-crystal superalloy. Corros. Sci. 2017, 123, 27-39. [CrossRef]

31. Wang, J.; Chen, M.; Zhu, S.; Wang, F. Ta effect on oxidation of a nickel-based single-crystal superalloy andits sputtered nanocrystalline coating at 900-1100 ${ }^{\circ}$ C. Appl. Surf. Sci. 2015, 345, 194-203. [CrossRef]

32. Wang, J.; Chen, M.; Yang, L.; Liu, L.; Zhu, S.; Wang, F.; Meng, G. The effect of yttrium addition on oxidation of a sputtered nanocrystalline coating with moderate amount of tantalumin composition. Appl. Surf. Sci. 2016, 366, 245-253. [CrossRef]

33. Zhu, C.; Javed, A.; Li, P.; Liang, G.; Xiao, P. Study of the effect of laser treatment on the initial oxidation behaviour of Al-coated NiCrAlY bond-coat. Surf. Interface Anal. 2013, 45, 1680-1689. [CrossRef]

34. Gong, X.; Chen, R.; Wang, Q.; Wang, Y.; Zhang, N.; Zhang, Z.; Fu, H. Cyclic oxidation behavior and oxide scale adhesion of Al/NiCrAlY coating on pure titanium alloy. J. Alloys Compd. 2017, 729, 679-687. [CrossRef]

35. Yu, P.; Wang, W.; Wang, F.; Zhu, S. High-temperature corrosion behavior of sputtered K38 nanocrystalline coatings with and without yttrium addition in molten sulfate at $900^{\circ} \mathrm{C}$. Surf. Coat. Technol. 2011, 206, 68-74. [CrossRef]

36. Lou, H.; Wang, F.; Xia, B.; Zhang, L. High-temperature oxidation resistance of sputtered micro-grain superalloy K38G. Oxid. Met. 1992, 38, 299-307. [CrossRef]

37. Chen, M.; Zhu, S.; Wang, F. High temperature oxidation of NiCrAlY, nanocrystalline and enamel-metal nano-composite coatings under thermal shock. Corros. Sci. 2015, 100, 556-565. [CrossRef]

38. Richard, C.; Béranger, G.; Lu, J.; Flavenot, J. The influences of heat treatments and interdiffusion on the adhesion of plasma-sprayed NiCrAlY coatings. Surf. Coat. Technol. 1996, 82, 99-109. [CrossRef]

39. Li, M.; Qian, Y.; Zhou, Y. Oxidation of pre-oxidized GH128 alloy implanted with $\mathrm{Ce}^{+}$at $1000{ }^{\circ} \mathrm{C}$. Trans. Nonferrous Met. Soc. China 2008, 18, 493-498. [CrossRef]

40. Pint, B.; Alexander, K. Grain boundary segregation of cation dopants in $\alpha-\mathrm{Al}_{2} \mathrm{O}_{3}$ layer. J. Electrochem. Soc. 1998, 145, 1819-1829. [CrossRef]

41. Guo, C.; Zhou, F.; Chen, M.; Wang, J.; Zhu, S.; Wang, F. An in-situ formed ceramic/alloy/ceramic sandwich barrier to resist elements interdiffusion between NiCrAlY coating and a Ni-based superalloy. J. Mater. Sci. Technol. 2020, 70, 1-11. [CrossRef]

42. Yu, P.; Shi, L.; Wang, W.; Wang, F.H. Oxidation Behavior of K38 Superalloy with Different Amounts of Yttrium Addition at 1173K in Air. Adv. Mater. Res. 2011, 366, 40-44. [CrossRef] 
43. Liao, Y.; Zhang, B.; Chen, M.; Feng, M.; Wang, W.; Zhu, S.; Wang, F. Self-healing metal-enamel composite coating and its protection for TiAl alloy against oxidation under thermal shock in $\mathrm{NaCl}$ solution. Corros. Sci. 2020, 167. [CrossRef]

44. Choi, H.; Jedlinski, J.; Yao, B.; Sohn, Y. Transmission electron microscopy observations on the phase transformation and microstructure of the oxidation scale growth on as-polished and yttrium implanted $\beta$-NiAl. Surf. Coat. Technol. 2010, 205, 1206-1210. [CrossRef]

Publisher's Note: MDPI stays neutral with regard to jurisdictional claims in published maps and institutional affiliations.

(C) 2020 by the authors. Licensee MDPI, Basel, Switzerland. This article is an open access article distributed under the terms and conditions of the Creative Commons Attribution (CC BY) license (http://creativecommons.org/licenses/by/4.0/). 